\title{
Cartilage Restoration for Tibiofemoral Bipolar Lesions Results in Promising Failure Rates: A Systematic Review
}

\author{
Anirudh K. Gowd, M.D., Alexander E. Weimer, B.S., Danielle E. Rider, B.S., \\ Edward C. Beck, M.D., M.P.H., Avinesh Agarwalla, M.D., Lisa K. O'Brien, D.O., \\ Michael J. Alaia, M.D., Cristin M. Ferguson, M.D., and Brian R. Waterman, M.D.
}

\begin{abstract}
Purpose: The purpose of the present study is to systematically review the available literature for management of bipolar lesions within the tibiofemoral joint and determine whether tibiofemoral cartilage restoration is an effective treatment modality. Methods: PubMed and MEDLINE databases were queried between 2000 and 2020 using the following keywords: "osteochondral" and "knee" and "microfracture," “autologous chondrocyte implantation (ACI)," or "transplantation." Articles were reviewed for the presence of a bipolar or "kissing" tibiofemoral lesion and reported lesion size, concomitant procedures, failure rates, and time to failure. Results: After screening 1,295 articles, there were 4 articles available for analysis and a total of 152 knees involving the management of bipolar tibiofemoral lesions. Age ranged from 14 to 60 years, and mean follow-up was between 12 and 240 months. There was 1 retrospective cohort study (36 knees) and 3 case series (mean, $38.7 \pm 17.5$ knees). There were 58 knees treated with bipolar osteochondral allograft (OCA) transplantation, 58 knees treated with bipolar ACI, 20 knees treated with femoral OCA and tibial debridement, and 16 knees treated with femoral OCA and tibial microfracture. There were 37 failures (24.3\%): 16 patients (10.5\%) were converted to unicompartmental or total knee arthroplasty, 4 restorative procedures $(2.6 \%)$ were revised, and 8 patients $(1.6 \%)$ had unsatisfactory outcomes only. The remaining 15 failures $(9.9 \%)$ had an unspecified combination of objective failure. The mean rate of failure ranged between $0 \%$ and $44.1 \%\left(I^{2}=83.2 \%\right)$. The mean time to failure ranged between 2.7 and 4.1 years $\left(I^{2}=79.1 \%\right)$. Conclusions: Cartilage restoration, through both ACI and OCA, had failure rates between $0 \%$ and $44 \%$ in patients with bipolar lesions of the tibiofemoral compartment. Although a higher level of evidence is required to prove efficacy, the current study demonstrates midterm survivorship rates between $55 \%$ and $100 \%$, which may delay the need for secondary arthroplasty. Level of Evidence: Level IV, systematic review of Level IV studies.
\end{abstract}

$\mathbf{F}$ ocal chondral defects of the tibiofemoral compartment are highly prevalent and can be identified in over $60 \%$ of patients undergoing knee arthroscopy. ${ }^{1}$

From Wake Forest University Baptist Medical Center, Winston-Salem, North Carolina, U.S.A. (A.K.G., A.E.W., D.E.R., E.C.B., L.K.O., C.M.F., B.R.W.); Westchester Medical Center, Valhalla, New York, U.S.A. (A.A.); and New York University Langone Health, New York, New York, U.S.A. (M.J.A.).

The authors report that they have no conflicts of interest in the authorship and publication of this article. Full ICMJE author disclosure forms are available for this article online, as supplementary material.

Received July 5, 2020; accepted March 31, 2021.

Address correspondence to Anirudh K. Gowd, M.D., Department of Orthopedic Surgery, Wake Forest University Baptist Medical Center, 1 Medical Center Blvd, Winston-Salem, NC 27157, U.S.A. E-mail: anirudhkgowd@ gmail.com

(C) 2021 THE AUTHORS. Published by Elsevier Inc. on behalf of the Arthroscopy Association of North America. This is an open access article under the CC BY-NC-ND license (http://creativecommons.org/licenses/by-nc-nd/4.0/). 2666-061X/201056

https://doi.org/10.1016/j.asmr.2021.03.020
These chondral lesions can serve as a nidus for significant pain, loss of function and activity, and progression of osteoarthritis. Surgically, these pathologies are challenging to treat as they may stem from varying causes, including trauma, malalignment, meniscal deficiency, ligamentous insufficiency, or vascular compromise; they are further compounded by the poor healing properties of cartilage. ${ }^{2,3}$ Bipolar, or "kissing," lesions are defined as reciprocal lesions within the same compartment of the knee and represent advanced pathology that has even greater risk of progression to osteoarthritis. ${ }^{4,5}$ Research aimed at joint preservation and operative technique is of significant value to activity restoration to certain patient populations, particularly when they do not meet criteria for knee arthroplasty.

Historically, bipolar lesions were considered a relative contraindication to cartilage restoration procedures due to inferior outcomes. ${ }^{6}$ However, without treatment, these patients often demonstrate progression of disease 
until eventual arthroplasty. This may be a poor option for patients who desire a high level of activity or whose age precludes arthroplasty in the near future. Over the past 2 decades, large advancements have been made in knee preservation, primarily through more expansive use of osteochondral allograft (OCA) and autologous chondrocyte implantation (ACI) procedures alongside adjunctive realignment and meniscal preservation or transplantation procedures. ${ }^{7}$

Increasing information from case series has become available regarding the outcomes of treatment of bipolar tibiofemoral defects. Despite this, there is still no consensus on appropriate indications for treatment, procedures, and expected outcomes following treatment. The purpose of the present study is to systematically review the available literature for management of bipolar lesions within the tibiofemoral joint and determine whether tibiofemoral cartilage restoration is an effective treatment modality. Our hypothesis is that both OCA and ACI, when combined with realignment procedures, are viable options to treat bipolar lesions with a low failure rate at short- to midterm follow-up.

\section{Methods}

\section{Search Strategy}

A literature search was performed using PubMed and MEDLINE databases under PRISMA (Preferred Reporting Items for Systematic Reviews and Meta-analyses) guidelines to create a systematic review of the scientific literature from 2000 to 2020. The following keywords were used in the search: "osteochondral" AND "knee" AND "microfracture," "autologous chondrocyte implantation," OR "transplantation." The initial search was performed on November 17, 2019, and reviewed on March 1, 2020, for new articles. During full article review, references within included articles were reviewed to include additional articles not found in the initial literature search.

\section{Selection Criteria}

Two authors (D.E.R. and A.E.W.) reviewed the searched articles to determine inclusion and exclusion criteria. Articles were selected based on whether they reported clinical outcomes on bipolar or "kissing" lesions of either the medial or lateral tibiofemoral compartment. The treatment of multifocal lesions alone did not meet eligibility for article inclusion. Included articles specifically involved bipolar or "kissing" lesions and reported concurrent procedures, failure rates, lesion sizes, and patient-reported outcomes after surgery. Study designs included case series, cohort studies, and randomized controlled trials. Articles were included if a subset of their population examined bipolar lesions. Data were then extrapolated from these articles to specifically involve bipolar lesion patients.
Excluded articles were those not in English, not involving "bipolar" or "kissing" lesions of the tibia and femur or patella and femur, or those involving animal or cadaveric populations.

\section{Quality Evaluation}

As the literature search did not yield any randomized trials, the MINORS (Methodological Index for Nonrandomized Studies) checklist was used to evaluate the quality of nonrandomized surgical studies. Quality was assessed using 12 items on the checklist, 4 of which are applicable to comparative studies. The 4 additional criteria specific to comparative groups assessed bias present in articles when selecting cohorts. Scoring was on a scale from 0 to 2: 0 , not reported; 1 , reported but poorly done and/or inadequate; and 2, reported well and adequately done. Noncomparative studies had a maximum score of 16, while comparison studies had a maximum score of 24. Each study included was scored by 2 authors (D.E.R. and A.E.W.), and a third reviewer was used (A.K.G.) if there was a disagreement.

\section{Data Extraction}

Following inclusion/exclusion of all articles, full articles were reviewed for the following categories of information: (1) article information, (2) patient demographics and follow-up period, (3) osteochondral defect locations and size, (4) surgical technique used, (5) rate of failure, and (6) time to failure. Additionally, to account for implicit heterogeneity of articles, the definition of failure and individual conclusions of each article were collected for qualitative review.

\section{Statistical Analysis}

Statistical analysis was performed using RStudio software version 1.0.143 (R Foundation for Statistical Computing). The primary outcome collected was the rate of failure as determined by study authors. Secondary outcomes were time to failure in those patients who had experienced failure, rates of revision chondral procedure, rates of conversion to arthroplasty, rates of inferior objective outcomes, and varying indications for treatment. These outcomes were graphed via forest plots, and the $I^{2}$ index was used to measure heterogeneity. The DerSimonian-Laird estimator was used to determine treatment effect sizes. ${ }^{8}$ High levels of heterogeneity were expected due to the predominance of case series available for study, so a random-effects model was used. Articles were likely heterogeneous because of varying indications for surgery, different surgeries performed, differences in patient population, and varying levels of pathology. Pooled rates of failure and pooled time to failure were compared using a Wald test. Publication bias was evaluated using a funnel chart. The treatment effect was plotted on the x-axis, while the size of each study was plotted on the y-axis. 
Fig 1. Preferred Reporting Items for Systematic Reviews and Meta-Analyses diagram of included articles available for analysis regarding bipolar lesions in the knee.
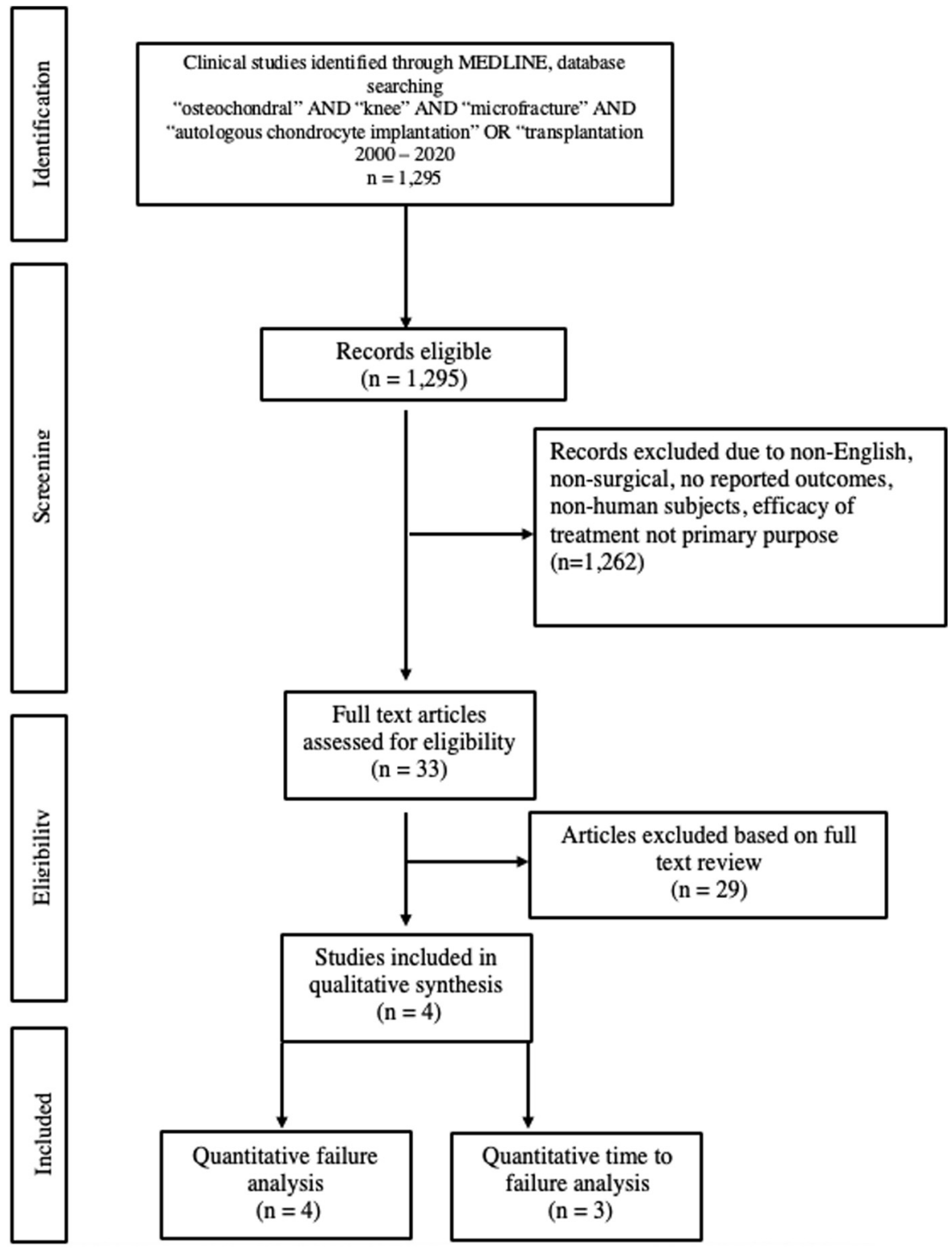

Full text articles assessed for eligibility $(\mathrm{n}=33)$

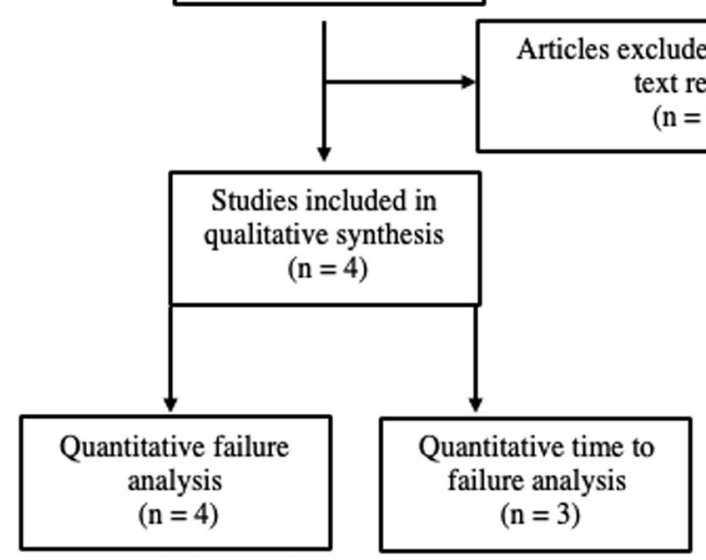

Point estimates were checked to be distributed evenly and symmetrically around the real effect of treatment to determine if no bias existed. ${ }^{9}$

\section{Results}

The initial search query yielded 1,295 articles. Following inclusion/exclusion criteria, there were 4 publications available for analysis (Fig 1). This included a total of 226 knees from 206 patients, 111 males and 95 females. However, only 152 knees were specifically identified with management of knees with bipolar or kissing lesions. The mean age was between 14 and 60 years, and mean follow-up ranged from 12 to 240 months. In total, there was 1 retrospective cohort study and 3 case series. The mean MINORS criteria were
$13.3 \pm 3.9$ (range, 11-19). Demographic information is summarized in Appendix 1 (available at WwW. arthroscopyjournal.org). Publication bias was assessed via funnel plot, which demonstrates symmetric alignment of treatment effect size failure rates. However, 2 populations are outside the projected funnel, which reflects article heterogeneity (Fig 2).

There were 63 procedures performed in the medial compartment, 65 performed in the lateral compartment, and 24 procedures that did not specify whether medial or lateral compartment. Indications for treatment and concomitant procedures are also summarized in Table 1. All articles reported total surface area of cartilage defects. The range in mean total surface area treated per article was 3.28 to $19.2 \mathrm{~cm}^{2}\left(I^{2}=98.2 \%\right)$. A 


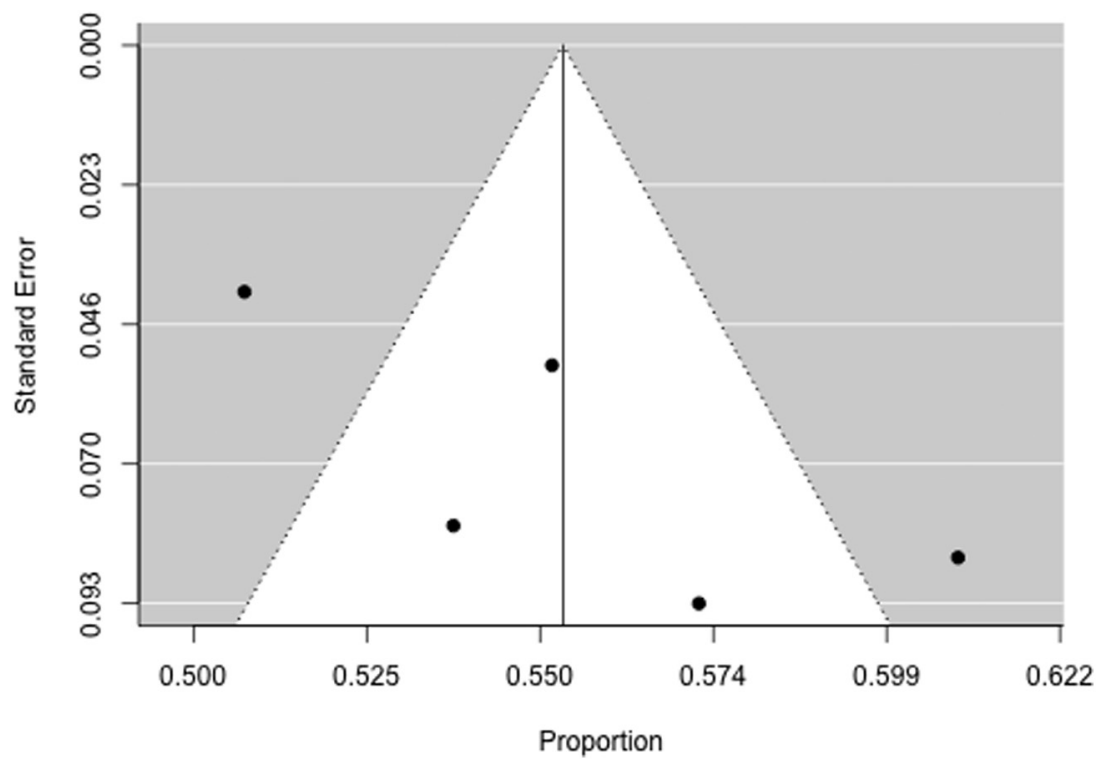

Fig 2. Funnel plot demonstrating publication bias in articles examining failure rates following treatment of bipolar cartilage defects.

single article reported mean lesion sizes within each compartment: $8.3 \pm 3.8 \mathrm{~cm}^{2}$ in the medial femoral condyle, $3.4 \pm 1.8 \mathrm{~cm}^{2}$ in the medial tibial plateau, $5.9 \pm 3.4 \mathrm{~cm}^{2}$ in the lateral femoral condyle, and $3.4 \pm 1.5 \mathrm{~cm}^{2}$ in the lateral tibial plateau (Fig 3). ${ }^{10}$

Three articles investigated OCA, including 1 study detailing results after femoral-sided OCA and either debridement or microfracture for the tibial-sided lesion.
A single article investigated ACI. This article used a combination of first-generation ACI with periosteum transplant as well as second-generation ACI with type I/ III collagen membrane. Concomitant procedures were highly prevalent among all included articles, including 67 meniscal allograft transplants, 32 high tibial osteotomies, 15 tibial tubercle osteotomies, 10 distal femoral osteotomies, 7 retinacular releases, 2 meniscectomies, 2

Table 1. Procedural Characteristics of Included Articles Regarding Management of Tibiofemoral Bipolar Lesions

\begin{tabular}{|c|c|c|c|c|}
\hline Author (Year) & $\begin{array}{l}\text { Lesion Location } \\
\text { (No.) }\end{array}$ & Procedure & $\begin{array}{c}\text { Concomitant } \\
\text { Procedures (No.) }\end{array}$ & Indications for Surgery \\
\hline Meric et al. $(2015)^{16}$ & $\begin{array}{l}\text { Medial (14) } \\
\text { Lateral (20) }\end{array}$ & OCA & $\begin{array}{l}\text { HWR (9) } \\
\text { RR (7) } \\
\text { Meniscectomy (2) } \\
\text { HTO (1) } \\
\text { DFO (1) }\end{array}$ & $\begin{array}{l}\text { Unspecified, included reciprocal } \\
\text { lesions in tibiofemoral joint, ICRS } \\
\text { III/IV, patients who failed other } \\
\text { therapies }\end{array}$ \\
\hline Getgood et al. $(2015)^{18}$ & TF (24) & OCA & $\operatorname{MAT}(48)^{*}$ & $\begin{array}{l}\text { Unspecified, included combined } \\
\text { osteochondral defect of femoral } \\
\text { condyle or tibial plateau and } \\
\text { meniscus deficiency }\end{array}$ \\
\hline $\begin{array}{l}\text { Hannon et al. }(2017)^{30} \\
\text { Debridement: } \\
\text { Microfracture: }\end{array}$ & $\begin{array}{l}\text { Medial (14) } \\
\text { Lateral (6) } \\
\text { Medial (3) } \\
\text { Lateral (13) }\end{array}$ & $\begin{array}{l}\text { OCA + tibial debridement } \\
\text { OCA + tibial microfracture }\end{array}$ & $\begin{array}{l}\text { Medial MAT (4) } \\
\text { Lateral MAT (2) } \\
\text { HTO (2) } \\
\text { DFO (2) } \\
\text { PLC (1) } \\
\text { Lateral MAT (12) } \\
\text { Medial MAT (1) } \\
\text { DFO (1) }\end{array}$ & $\begin{array}{l}\text { Skeletally mature patients with } \\
\text { symptomatic ICRS III/IV of femur } \\
\text { with reciprocal tibial defect }\end{array}$ \\
\hline Ogura et al. $(2018)^{10}$ & $\begin{array}{l}\text { Medial (32) } \\
\quad \text { Lateral (26) }\end{array}$ & $\begin{array}{c}\text { ACI (P-ACI, } \mathrm{n}=23) \\
(\mathrm{C}-\mathrm{ACI}, \mathrm{n}=35)\end{array}$ & $\begin{array}{l}\text { HTO (14) } \\
\text { TTO (9) } \\
\text { HTO + TTO }(15) \\
\text { DFO + TTO (6) }\end{array}$ & $\begin{array}{l}\text { Unspecified, included patients with } \\
\text { greater than } 1 \text { articular cartilage } \\
\text { defect }\end{array}$ \\
\hline
\end{tabular}

ACI, autologous chondrocyte implantation; C-ACI, collagen membrane autologous chondrocyte implantation; DFO, distal femoral osteotomy; HTO, high tibial osteotomy; HWR, hardware removal; ICRS, international cartilage regeneration \& joint preservation society; MAT, meniscus allograft transplantation; OCA, osteochondral allograft transplantation; P-ACI, periosteum autologous chondrocyte implantation; RR, retinacular release; TF, tibiofemoral; TTO, tibial tubercle osteotomy.

${ }^{*}$ Concomitant procedures were not separated by bipolar lesions. 
Total Lesion Size

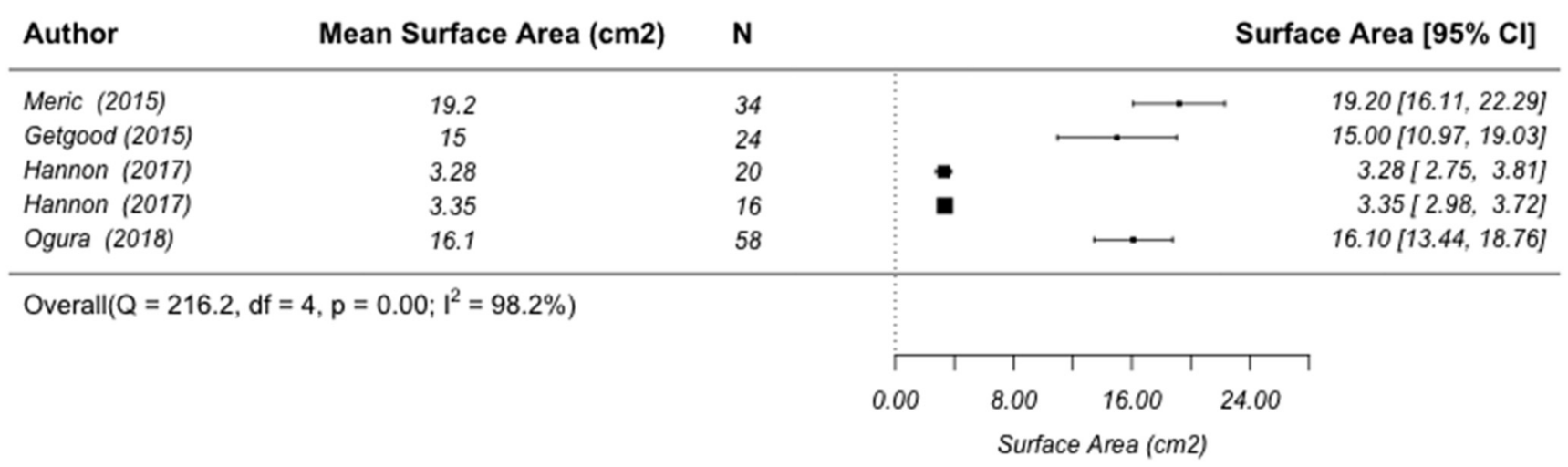

Fig 3. Total surface area of treated tibiofemoral chondral defects.

anterior cruciate ligament reconstructions, and 1 posterolateral corner operation performed alongside cartilage restoration. Of note, in articles with heterogeneous populations, concomitant procedures were not separated by lesion location.

Failure definitions and study conclusions are summarized in Table 2. In total, $37(24.3 \%)$ failures occurred. A revision cartilage restoration procedure (ACI: $\mathrm{n}=2$; OCA: $\mathrm{n}=2$ ) was performed in 4 cases $(2.6 \%)$. A total of 16 patients $(10.5 \%)$ were converted to unicompartmental $(\mathrm{n}=2)$, bicompartmental $(\mathrm{n}=1)$, or total $(\mathrm{n}=13)$ knee arthroplasty. Eight patients $(1.6 \%)$ had an unsatisfactory clinical outcome based on continued symptoms but chose not to undergo revision procedure or conversion to arthroplasty. The remaining 15 failures $(9.9 \%)$ had an unspecified combination of requiring revision OCA, arthroplasty, or arthrodesis after recurrent infection. The range in mean failure rate was $0 \%$ to $44.1 \%\left(I^{2}=83.2 \%\right)$. The range in mean time to failure was 2.7 to 4.1 years $\left(I^{2}=79.1 \%\right)$ (Fig 4).

\section{Discussion}

In 152 knees with bipolar or kissing lesions in the tibiofemoral compartment, the mean rate of failure ranged from $0 \%$ to $44.1 \%\left(I^{2}=83.2 \%\right)$ with an mean time to failure between 2.7 and 4.1 years $\left(I^{2}=79.1 \%\right)$. Operative management of these cartilage lesions is challenging due to the advanced state of pathology on presentation and sparsity of current literature. However, the findings of the present study would support the viability of cartilage restoration in the management of these lesions. Both ACI and OCA were used to treat large, bipolar lesions, often with mean cumulative surface areas greater than $10 \mathrm{~cm}^{2}$ in selected studies. Furthermore, the failure rate ranged between $0 \%$ to $44 \%$. In the event of failure, the elapsed time was typically greater than 2 years after the index surgery. While the current findings are limited by study heterogeneity, these results challenge the commonly held dogma indicating that the presence of bipolar lesions is an absolute contraindication to restorative procedures. Particularly when combined

Table 2. Definitions of Failure and Conclusions From Included Studies

\begin{tabular}{|c|c|c|c|}
\hline Author (Year) & LOE & Definition for Failure & Study Conclusions \\
\hline Meric et al. $(2015)^{16}$ & IV & $\begin{array}{l}\text { Revision allografting, conversion to } \\
\text { arthroplasty, arthrodesis }\end{array}$ & $\begin{array}{l}\text { Larger bipolar cartilage lesions represent later stage } \\
\text { of disease; caution should be taken when total } \\
\text { surface area of lesions is }>24.6 \mathrm{~cm}^{2} \text { (median size } \\
\text { of failures) }\end{array}$ \\
\hline Getgood et al. $(2015)^{18}$ & IV & Removal of osteochondral allograft & $\begin{array}{l}\text { Although not significant, trend toward better } \\
\text { outcomes in unipolar disease for combined } \\
\text { OCA + MAT }\end{array}$ \\
\hline Hannon et al. $(2017)^{30}$ & III & Revision allograft, TKA, arthrodesis & $\begin{array}{l}\text { Patients with bipolar defects treated with femoral } \\
\text { OCA have clinically meaningful improvements } \\
\text { despite tibial treatment }\end{array}$ \\
\hline Ogura et al. $(2018)^{10}$ & IV & $\begin{array}{l}\text { Persistent/recurrent symptom }+ \text { MRI } \\
\text { and/or arthroscopic evidence of failure }\end{array}$ & $\begin{array}{l}\text { ACI for treatment of bipolar lesions was successful; } \\
\text { use of a collagen membrane led to greater } \\
\text { survival than periosteum }\end{array}$ \\
\hline
\end{tabular}

ACI, autologous chondrocyte implantation; LOE, level of evidence; MAT, meniscus allograft transplantation; MRI, magnetic resonance imaging; OCA, osteochondral allograft transplantation; TKA, total knee arthroplasty. 
Incidence of Failures

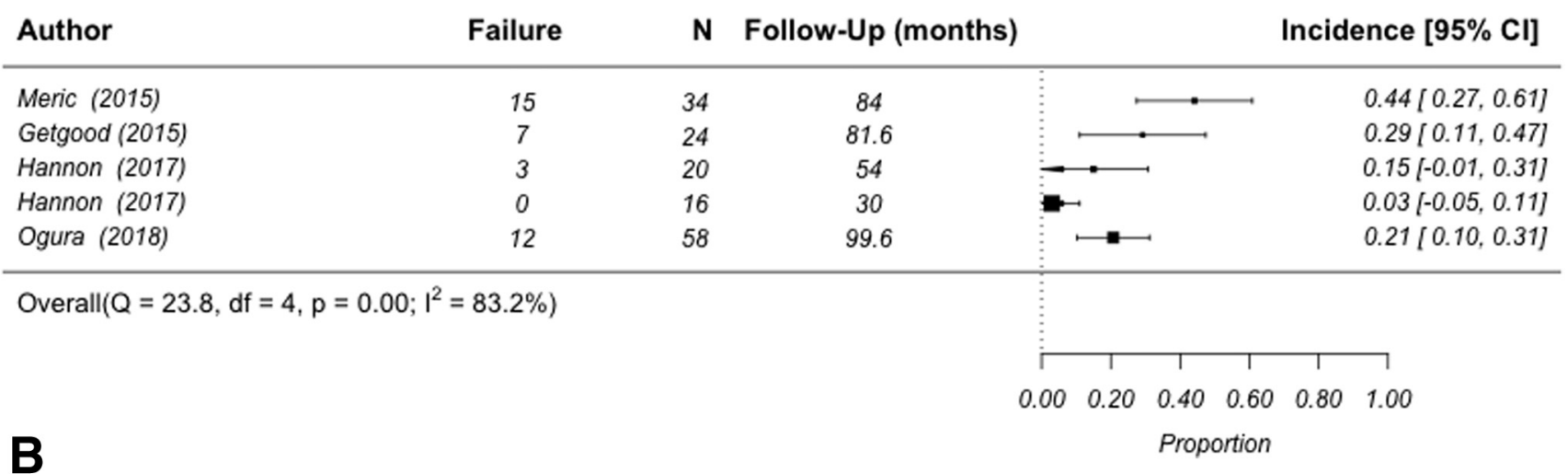

Time to Failure

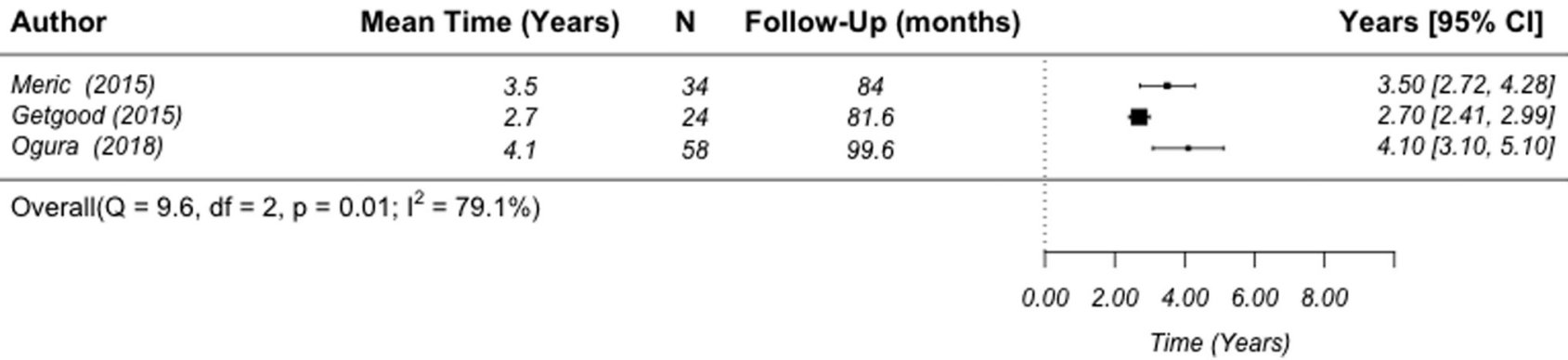

Fig 4. (A) Incidence of failure by procedure and (B) time to failure.

with appropriate realignment and other restorative procedures, operative management may significantly delay the need for secondary arthroplasty, improve patient-reported function, and preserve overall quality of life.

While the study findings suggest that bipolar lesions are treatable, patient selection for this procedure remains a difficult challenge. Among included articles, there remains an area of inconclusive evidence without consensus. Age and activity level may be considered relative indications as these may preclude alternative reconstructive options for patients. Mean age between all articles ranged from 27.0 to 40.2 years. Clinical outcomes, particularly regarding return to sport and failure rates, are improved in younger patients with acute injuries. ${ }^{1-15}$ This may also be due to the fact that younger patients have less degenerative changes in the knee outside the focal defects. Lesion size is another consideration as both ACI and OCA are invasive procedures that are reserved for medium to large cartilage defects of greater than 2 $\mathrm{cm}^{2}{ }^{2,3}$ A maximum threshold for treatment has also not been thoroughly discussed; however, Meric et al. ${ }^{16}$ affirmed that total lesion size above $24.6 \mathrm{~cm}^{2}$ may not be amenable to restoration. While this is an arbitrary cutoff based off a single series, this does represent a very large area of disease burden. In such cases, it remains difficult to assess focal chondral defects vs degenerative arthrosis in progression, and further research may be necessary to discern consistent predictors of failure.

Distinguishing patients with advanced focal cartilage disease vs those with initial signs of irreversible arthritis remains a challenge, especially with regard to allocating appropriate treatment. Osteoarthritis of the knee constitutes a progressive disease characterized by osteophyte formation, degeneration of articular cartilage matrix, subchondral bone sclerosis, and deformity of the bone contour. ${ }^{1,17}$ Giannini et al. ${ }^{12}$ suggest that graft failure may be elicited by immunologic rejection by catabolic factors already present in arthritic knees. Interestingly, both Meric et al. ${ }^{16}$ and Getgood et al. ${ }^{18}$ found a higher proportion of failures in patients treated for degenerative bipolar chondral lesions, albeit this was not statistically significant. Continued analysis of synovial fluid cytokines may provide valuable insight in selecting patients with the least likelihood to reject implantation. ${ }^{19}$ 
The effect of realignment procedures should also not be underscored in management of tibiofemoral bipolar lesions. Varus and valgus alignment places excess stress on medial and lateral weightbearing surfaces, respectively, and can be influential in both creating the reciprocal lesions or causing the donor graft to fail. ${ }^{20}$ High tibial osteotomy alone has been shown to result in partial cartilage repair at an incidence of $16 \%$ to $92 \%$, demonstrating the efficacy of realignment itself. ${ }^{21-24} \mathrm{Kim}$ et al. ${ }^{22}$ found that bipolar lesions greater than $1.5 \mathrm{~cm}$ were not amenable to repair by high tibial osteotomy alone. In their institutional analysis of failures among cartilage repair procedures, Krych et al. ${ }^{25}$ highlighted that untreated malalignment was the most common reason. An expert panel on cartilage restoration deemed concurrent anatomic abnormalities to be of utmost importance to be corrected during the cartilage restoration procedure. ${ }^{26}$ The biomechanical literature has demonstrated that unloading procedures can reduce joint surface pressures by up to $30 \% .^{27-29}$ To this note, Black et al. ${ }^{28}$ also remark on the importance of controlling tibial slope to prevent unwanted loads to the tibial plateau. Included articles had a high prevalence of realignment procedures through soft tissue release and osteotomy that help explain the low rate of failures despite the high level of pathology. From the available literature, it is challenging to determine whether success in intervention for tibiofemoral bipolar lesions may be attributed to correction of varus/valgus alignment vs cartilage restoration.

Further, advances in meniscus preservation and restoration have improved the success of cartilage repair. ${ }^{18,30,31}$ Anatomically or functionally meniscusdeficient patients are predisposed to increased contact pressures and, as a result, attritional cartilage loss. ${ }^{32,33}$ Meniscal surgery, either through transplant or repair, has significantly increased over the past decade, even with cartilage restoration procedures. ${ }^{34-37}$ Addressing the meniscus allows repaired cartilage to have the greatest likelihood of successful implantation and preservation of joint integrity. ${ }^{38}$ Lee et al. ${ }^{39}$ performed meniscal allograft transplant (MAT) alone on 222 patients and found this treatment to be effective in managing patients with advanced cartilage disease. The failure rate for isolated MAT was $11.3 \%$, but this increased to $23 \%$ in patients with high-grade bipolar defects. ${ }^{39}$ Harris et al. ${ }^{40}$ reported significant improvements on an initial series of patients who received combined corrective osteotomy, MAT, and articular cartilage restoration. In their series, the authors reported a $5.6 \%$ rate of conversion to total knee arthroplasty and a $5.6 \%$ revision of either MAT or an articular cartilage procedure. ${ }^{40}$ The triad of malalignment, meniscal deficiency, and articular cartilage disease may be treated either staged to reduce morbidity or in a combined procedure based on multifactorial decision making. These findings echo the advanced state of pathology in patients with bipolar lesions, in whom extensive restorative procedures may be required to prevent the eventual progression of arthritis and need for arthroplasty. Despite qualitative review of the literature and assessment of individual study conclusions, further clinical trials are required to demonstrate the efficacy of cartilage restoration upon bipolar defects, particularly as it pertains to delaying the normal degenerative process of the knee. Additional study is also required for optimizing patient selection and differentiating between the use of ACI vs OCA, as the included articles did not shed light on this decision-making process.

\section{Limitations}

The present study must acknowledge certain limitations. There is a high level of heterogeneity with respect to the included articles. Articles varied with regard to demographics, follow-up time, indications for surgery, operations performed, pathologies treated, and definitions for success and failure. Furthermore, very few studies had comparative cohorts.

\section{Conclusions}

Cartilage restoration, through both ACI and OCA, had failure rates between $0 \%$ and $44 \%$ in patients with bipolar lesions of the tibiofemoral compartment. Although a higher level of evidence is required to prove efficacy, the current study demonstrates midterm survivorship rates between $55 \%$ and $100 \%$, which may delay the need for secondary arthroplasty.

\section{References}

1. Houck DA, Kraeutler MJ, Belk JW, Frank RM, McCarty EC, Bravman JT. Do focal chondral defects of the knee increase the risk for progression to osteoarthritis? A review of the literature. Orthop J Sports Med 2018;6: 2325967118801931.

2. Cavendish PA, Everhart JS, Peters NJ, Sommerfeldt MF, Flanigan DC. Osteochondral allograft transplantation for knee cartilage and osteochondral defects: A review of indications, technique, rehabilitation, and outcomes. JBJS Rev 2019;7:e7.

3. Krill M, Early N, Everhart JS, Flanigan DC. Autologous chondrocyte implantation (ACI) for knee cartilage defects: A review of indications, technique, and outcomes. JBJS Rev 2018;6:e5.

4. Davies-Tuck ML, Wluka AE, Wang Y, et al. The natural history of cartilage defects in people with knee osteoarthritis. Osteoarthritis Cartilage 2008;16:337-342.

5. Messner K, Maletius W. The long-term prognosis for severe damage to weight-bearing cartilage in the knee: A 14-year clinical and radiographic follow-up in 28 young athletes. Acta Orthop Scand 1996;67:165-168. 
6. Versier G, Dubrana F, French Arthroscopy Society. Treatment of knee cartilage defect in 2010. Orthop Traumatol Surg Res OTSR 2011;97:S140-S153. suppl.

7. Redondo ML, Naveen NB, Liu JN, Tauro TM, Southworth TM, Cole BJ. Preservation of knee articular cartilage. Sports Med Arthrosc Rev 2018;26: e23-e30.

8. DerSimonian R, Laird N. Meta-analysis in clinical trials revisited. Contemp Clin Trials 2015:45:139-145 (pt A).

9. Egger M, Davey Smith G, Schneider M, Minder C. Bias in meta-analysis detected by a simple, graphical test. BMJ 1997;315:629-634.

10. Ogura T, Bryant T, Mosier BA, Minas T. Autologous chondrocyte implantation for bipolar chondral lesions in the tibiofemoral compartment. Am J Sports Med 2018;46: 1371-1381.

11. Demange M, Gomoll AH. The use of osteochondral allografts in the management of cartilage defects. Curr Rev Musculoskelet Med 2012;5:229-235.

12. Giannini S, Buda R, Ruffilli A, et al. Failures in bipolar fresh osteochondral allograft for the treatment of endstage knee osteoarthritis. Knee Surg Sports Traumatol Arthrosc 2015;23:2081-2089.

13. Minas T, Bryant T. The role of autologous chondrocyte implantation in the patellofemoral joint. Clin Orthop 2005:436:30-39.

14. Minas T, Gomoll AH, Solhpour S, Rosenberger R, Probst C, Bryant T. Autologous chondrocyte implantation for joint preservation in patients with early osteoarthritis. Clin Orthop 2010;468:147-157.

15. Mithoefer K, Williams RJ, Warren RF, Wickiewicz TL, Marx RG. High-impact athletics after knee articular cartilage repair: A prospective evaluation of the microfracture technique. Am J Sports Med 2006;34:1413-1418.

16. Meric G, Gracitelli GC, Görtz S, De Young AJ, Bugbee WD. Fresh osteochondral allograft transplantation for bipolar reciprocal osteochondral lesions of the knee. Am J Sports Med 2015;43:709-714.

17. Kellgren JH, Lawrence JS. Radiological assessment of osteo-arthrosis. Ann Rheum Dis 1957;16:494-502.

18. Getgood A, Gelber J, Gortz S, De Young A, Bugbee W. Combined osteochondral allograft and meniscal allograft transplantation: A survivorship analysis. Knee Surg Sports Traumatol Arthrosc 2015;23:946-953.

19. Schmal H, Mehlhorn AT, Dovi-Akue D, Pestka JM, Südkamp NP, Niemeyer P. Correlation of synovial cytokine expression with quality of cells used for autologous chondrocyte implantation in human knees. Eur J Orthop Surg Traumatol Orthop Traumatol 2014;24:1563-1570.

20. Vasiliadis HS, Lindahl A, Georgoulis AD, Peterson L. Malalignment and cartilage lesions in the patellofemoral joint treated with autologous chondrocyte implantation. Knee Surg Sports Traumatol Arthrosc 201 1; 19: 452-457.

21. Jung W-H, Takeuchi R, Chun C-W, et al. Second-look arthroscopic assessment of cartilage regeneration after medial opening-wedge high tibial osteotomy. Arthrosc $J$ Arthrosc Relat Surg 2014;30:72-79.

22. Kim C-W, Seo S-S, Lee C-R, Gwak H-C, Kim J-H, Jung S-G. Factors affecting articular cartilage repair after open-wedge high tibial osteotomy. Knee 2017;24:1099-1107.
23. Koshino T, Wada S, Ara Y, Saito T. Regeneration of degenerated articular cartilage after high tibial valgus osteotomy for medial compartmental osteoarthritis of the knee. Knee 2003;10:229-236.

24. Matsunaga D, Akizuki S, Takizawa T, Yamazaki I, Kuraishi J. Repair of articular cartilage and clinical outcome after osteotomy with microfracture or abrasion arthroplasty for medial gonarthrosis. Knee 2007;14: 465-471.

25. Krych AJ, Hevesi M, Desai VS, Camp CL, Stuart MJ, Saris DBF. Learning from failure in cartilage repair surgery: An analysis of the mode of failure of primary procedures in consecutive cases at a tertiary referral center. Orthop J Sports Med 2018;6:2325967118773041.

26. Chahla J, Hinckel BB, Yanke AB, et al. An expert consensus statement on the management of large chondral and osteochondral defects in the patellofemoral joint. Orthop J Sports Med 2020;8:2325967120907343.

27. Beck PR, Thomas AL, Farr J, Lewis PB, Cole BJ. Trochlear contact pressures after anteromedialization of the tibial tubercle. Am J Sports Med 2005;33:1710-1715.

28. Black MS, d'Entremont AG, McCormack RG, Hansen G, Carr D, Wilson DR. The effect of wedge and tibial slope angles on knee contact pressure and kinematics following medial opening-wedge high tibial osteotomy. Clin Biomech 2018;51:17-25.

29. Rue J-PH, Colton A, Zare SM, et al. Trochlear contact pressures after straight anteriorization of the tibial tuberosity. Am J Sports Med 2008;36:1953-1959.

30. Hannon CP, Weber AE, Gitelis M, Meyer MA, Yanke AB, Cole BJ. Does treatment of the tibia matter in bipolar chondral defects of the knee? Clinical outcomes with greater than 2 years follow-up. Arthroscopy 2018;34: 1044-1051.

31. Stannard JP, Cook JL. Prospective assessment of outcomes after primary unipolar, multisurface, and bipolar osteochondral allograft transplantations in the knee: A comparison of 2 preservation methods. Am J Sports Med 2020;48:1356-1364.

32. Kurosawa H, Fukubayashi T, Nakajima H. Load-bearing mode of the knee joint: physical behavior of the knee joint with or without menisci. Clin Orthop 1980;149: 283-290.

33. Wang Y-XJ, Griffith JF, Ahuja AT. Non-invasive MRI assessment of the articular cartilage in clinical studies and experimental settings. World J Radiol 2010;2: 44-54.

34. Bonazza NA, Smuin DM, Joshi R, et al. Surgical trends in articular cartilage injuries of the knee, analysis of the Truven Health MarketScan commercial claims database from 2005-2014. Arthrosc Sports Med Rehabil 2019;1: el01-el07.

35. Gomoll AH, Kang RW, Chen AL, Cole BJ. Triad of cartilage restoration for unicompartmental arthritis treatment in young patients: Meniscus allograft transplantation, cartilage repair and osteotomy. J Knee Surg 2009;22:137-141.

36. Pekari TB, Wang KC, Cotter EJ, Kusnezov N, Waterman BR. Contemporary surgical trends in the management of symptomatic meniscal tears among United States military servicemembers from 2010 to 2015. J Knee Surg 2019;32:196-204. 
37. Suchman KI, Behery OA, Mai DH, Anil U, Bosco JA. The demographic and geographic trends of meniscal procedures in New York State: An analysis of 649,470 patients over 13 years. J Bone Joint Surg Am 2018;100: $1581-1588$.

38. Hutchinson ID, Moran CJ, Potter HG, Warren RF, Rodeo SA. Restoration of the meniscus: form and function. Am J Sports Med 2014;42:987-998.
39. Lee B-S, Bin S-I, Kim J-M, Kim W-K, Choi JW. Survivorship after meniscal allograft transplantation according to articular cartilage status. Am J Sports Med 2017;45: 1095-1101.

40. Harris JD, Hussey K, Wilson H, et al. Biological knee reconstruction for combined malalignment, meniscal deficiency, and articular cartilage disease. Arthroscopy 2015;31:275-282. 